\title{
Cost Accounting and Analysis for University Libraries
}

\begin{abstract}
The approach to library planning studied in this paper is the use of accounting models to measure library costs and implement program budgets. A cost-flow model for a university library is developed and tested with historical data from the General Library at the University of California, Berkeley. Various comparisons of an exploratory nature are made of the unit costs and total costs for different parts of the Berkeley system.
\end{abstract}

The Cost-Flow Accounting Model

$\mathrm{T}$ HERE DOES NOT APPEAR to be any uniform method by which libraries account for their internal costs. Considerable attention is given to the development of budgets along organizational lines and to the control of expenditures for labor and materials. But these data are not used to measure the cost of performing some function or rendering some service in the manner of industrial cost accounting. For example, in order to estimate the cost of holding a journal and to compare it with the cost of using a regional lending service, Williams ${ }^{4}$ had to develop his own basic data in four libraries by means of interviews and other sampling techniques. In their re-

Dr. Leimkuhler is Dean of the School of Industrial Engineering, Purdue University, Lafayette, Indiana, and Dr. Cooper is assistant professor at the School of Librarianship, University of California, Berkeley.

This work was supported by a Ford Foundation grant no. 68-267 (Research Projects in University Administration) to the Office of the Vice-President-Planning and Analysis, University of California, Berkeley. Copies of the full report may be obtained from Dr. Cooper. cent study of the M.I.T. Libraries, Raffel and Shishko ${ }^{3}$ had to augment the existing data base considerably in order to estimate the cost of various library functions and programs. In addition, the papers of Penner ${ }^{2}$ and Landau ${ }^{1}$ provide a good review of previous cost studies.

A basic notion in the development of a cost control system is the idea of a "cost center" for which there is a clear definition of function and responsibility. The cost centers serve as focal points in the system for the collection and evaluation of cost data. There appear to be two major kinds of cost centers in libraries: processing centers and service centers. The processing centers serve an intermediate role in the flow of resources to the service centers, and all of their costs are passed on to the service units. The service centers can include branch libraries or specialized facilities within a central library. These units offer a schedule of services to certain users at certain "prices" which together comprise the output of the library. A library program may be identified with a single service unit or may cut across several or all units. Shishko divided the mission of the M.I.T. Libraries between research and instruction without subdi- 
viding it by subject area. In a branch library system most branches would contribute to both research and instructional programs and their individual output would have to be divided under the two main headings, if this is desired. In accounting for costs and developing costs of service estimates it is important that these figures be related to a true decision-making function in the organization; that is, they should have a quality called "accountability." It is meaningless to develop numbers about which nothing can be done.

A simplified cost accounting plan for modelling the flow of cost through a library organization is shown in Figure 1. This plan incorporates the notion of standard cost as a measure of performance. The standard costs are based on the number of items processed, acquired, or held by the library unit. Other measures of performance could be used to gauge the flow of costs. These standards should be evaluated each year and modified accordingly so as to provide the best estimate of what is expected for the next year. "Variance" accounts can be used to collect the difference between what is expected and actually occurs; that is, between standard cost and "full" cost. This is a common and useful way to maintain control over costs and to generate management-byexception reports. In Figure 1 only one variance account is shown for each category, but in practice one may develop separate variance measures for the amount and the unit cost of a flow. For example, if labor is costed at different wage rates for different kinds of labor hours used, it would be possible to maintain separate variance accounts for the wage rate and the labor hours to explain total labor variance. Standard costing assumes that the cost is directly proportional to the basis for unit cost; however, routine corrections can be made to account for any predictable bias from the variance figures.

\section{A Cost Model of the BERKELEy LibraRIES}

The cost accounting plan in Figure 1 was applied to the Libraries of the University of California at Berkeley in order to show how costs are generated and flow through the system to the various branch and special libraries. The resulting simplified cost model of the Berkeley Libraries is shown in Figure 2. No variance accounts are included in this model, since it is based on the cost history of a single year. However, variance accounts and standard costing could be introduced. The model conforms closely to the organizational structure of the Berkeley Libraries except in the case of the Serials and Documents Department, where a division had to be made between their function as a central processing unit and their function as a special service unit for readers. A similar division was made at the branch libraries to separate the cost of selecting and accessioning new items from the cost of maintaining and providing service from the shelved collection.

The main kinds of costs in the model are the direct costs for materials and labor and the indirect costs for space and overhead. The costs of space and university overhead do not enter into the ordinary budget estimates of operating costs, but they are important parts of the total cost of operating libraries and cannot be ignored. All space for the libraries was costed at the same unit price except for the depository space, and the university overhead was applied at a uniform rate. This permitted the development of a total labor, space, and overhead figure for each organizational unit of the library.

The main distinction in the flow of materials is between monographs and serials, and between purchased items and gift and exchange items, although the latter distinction is dropped after acquisition processing. For serials, a dis- 


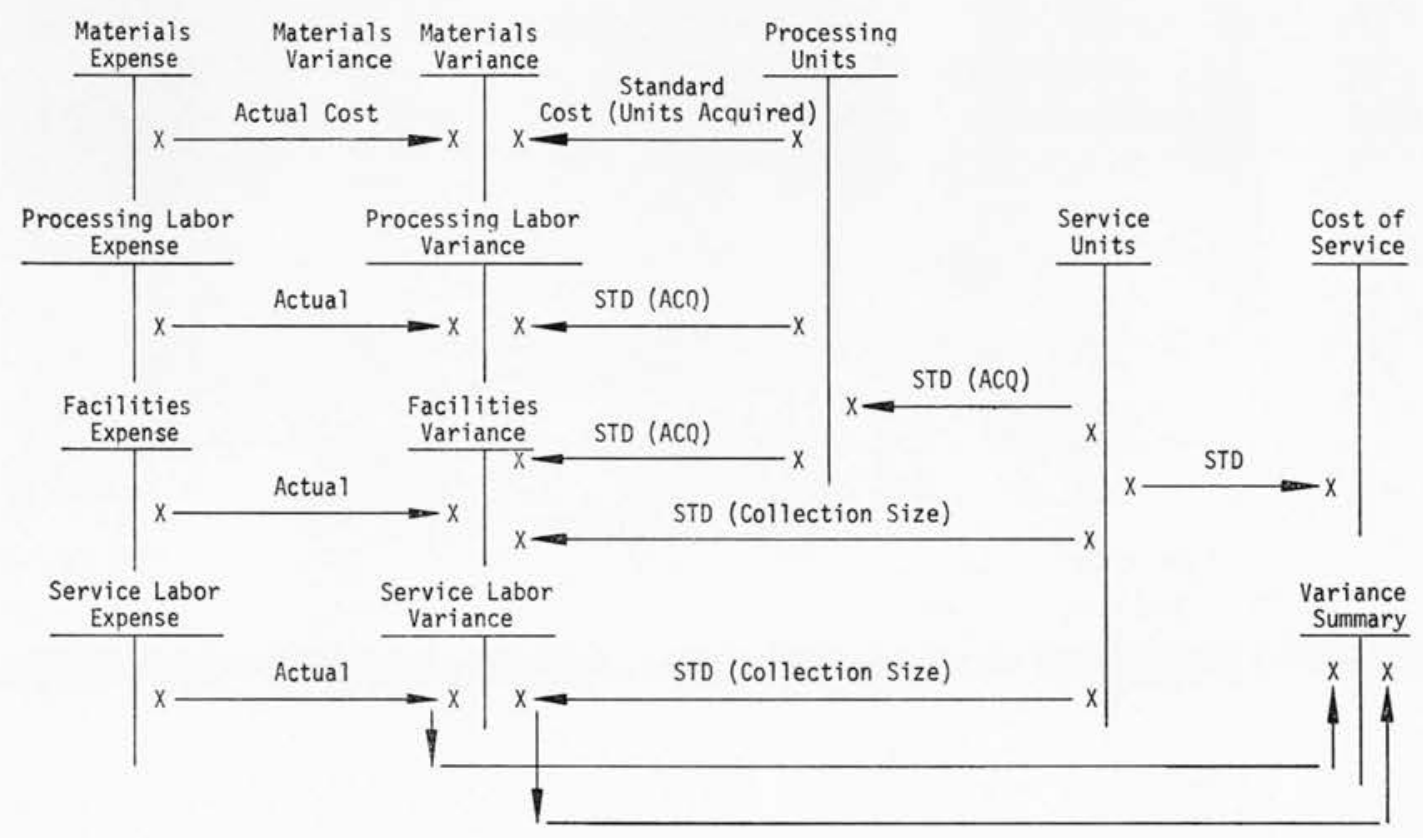

Figure 1

Flow of Library Costs in a Simplified Standard Cost Accounting Plan

tinction is maintained between new items and continuing items because of the difference in cataloging treatment. The total number of items and their distribution through the system are based on data from the annual reports of the Berkeley Libraries for the year July 1, 1967, to June 30, 1968 (1967/ 1968 ), although in some instances it was necessary to develop estimates from the Libraries' files of orders.

\section{Direct Costs: Materials}

Materials costs for the Berkeley library are limited to two classes of items: monographs and serials. Any type of library material for which a standing order can be placed is considered a serial.

Through the budgeting process each branch library is allocated money for purchase of monographs. For each branch a branch fund is maintained from which all disbursements are made. In all, more than 150 funds are used for materials purchasing for the General Library.

Each order for a monograph may call for the receipt of one or more volumes. A random sampling procedure was undertaken to determine the number of volumes per order. Eighteen hundred orders from thirteen funds were examined. From this data, the number of volumes per order was determined to be 1.20. Certain funds such as those used to buy back sets and serials and duplicate copies of high usage monographs had significantly different ratios-2.20 for both. For these funds, the latter factor was used.

Table 1 summarizes the number of monographs acquired during the fiscal year 1967/1968. The average price per monograph for the Berkeley General Library was $\$ 7.44$, for a total of 81,350 items acquired. The number of items acquired by the branches was 21 percent of the total, while expenditures were 20 percent of the total $(\$ 605,588)$. 


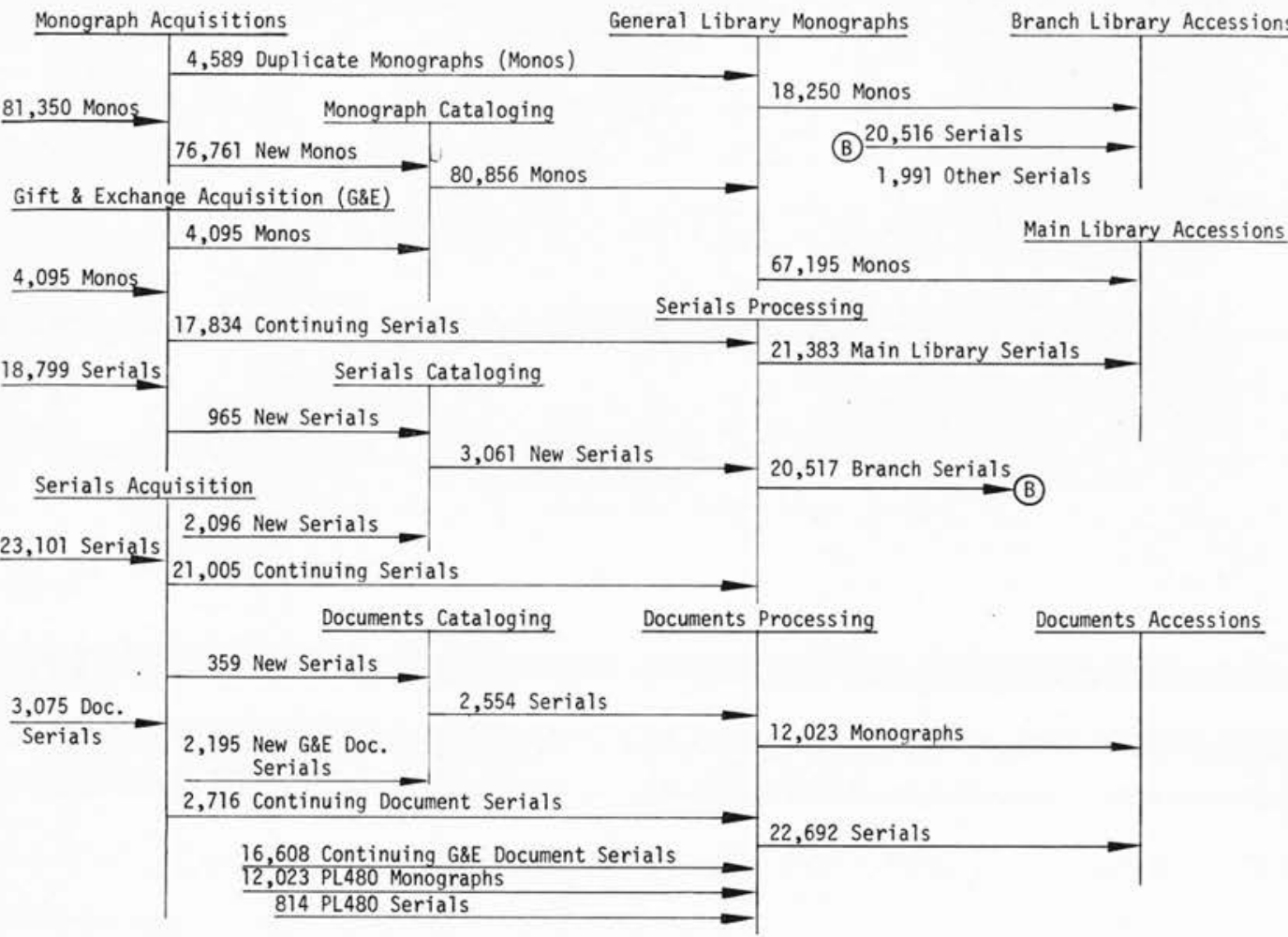

Figure 2

Items Processed

A second category of materials that enter into the library system is serials. To determine the average price per paid serial for the libraries, a sample of the order file of 25,450 cards was taken. Of the 1,378 orders (5.4 percent) examined, 975 (3.8 percent) were found to be related to items received and paid for in the 1967/1968 fiscal year. The results of the sample are also shown in Table 1 . The average price of a serial received by a branch library was $\$ 27.23$ while all other General Library units averaged $\$ 13.13$ per serial. The overall average price per serial was $\$ 20.01$.

Williams [1968] reports that for the four university libraries he sampled, the subscription prices per title year were $\$ 12.62, \$ 22.62$, $\$ 21.55$, and $\$ 17.06$.

In addition to paid serials representing 54 percent of the total received, more than 19,000 serials are received through gift and exchange operations. Table 2 shows the distribution of all serial items across branches.

\section{Direct Costs: LABOR}

Aside from materials cost, the second component of direct costs is labor. The Berkeley library divides the labor force into three classes: professional, nonprofessional, and general assistance. Almost all student employees are hired in the general assistance category. Mean salary rates per year for each category are shown in Table 3. The nonprofessional category includes the "library assistant" job titles as well as secretary, bookmender, editor, etc.

Organization charts for the library, in conjunction with published salary 
TABLE 1

\begin{tabular}{|c|c|c|c|c|c|c|}
\hline हే & 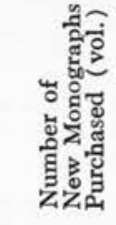 & 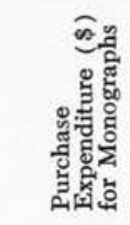 & 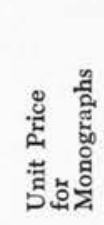 & 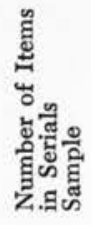 & 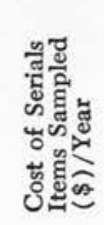 & 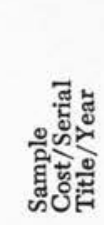 \\
\hline & 790 & 5,879 & 7.44 & 48 & 2,682 & 55.88 \\
\hline $\mathrm{y}(\mathrm{A} / \mathrm{A})$ & 812 & 5,217 & 6.42 & 13 & 96 & 7.38 \\
\hline $\mathrm{h} /$ Stat (AMS) & 390 & 3,550 & 9.10 & 15 & 309 & 20.60 \\
\hline BIOCHEM) & 72 & 930 & 12.92 & 9 & 231 & 25.67 \\
\hline & 658 & 6,358 & 9.66 & 76 & 2,848 & $37.47^{2}$ \\
\hline EM) & 181 & 2,373 & 13.11 & 22 & 535 & 24.32 \\
\hline (ES) & 489 & 4,065 & 8.31 & 9 & 85 & 9.44 \\
\hline AL) & 4,665 & 21,620 & 4.63 & 28 & 455 & 16.25 \\
\hline hology $(E / P)$ & 1,841 & 9,878 & 5.37 & 40 & 351 & 8.78 \\
\hline NG) & 713 & 8,670 & 12.16 & 55 & 2,118 & 38.51 \\
\hline ENT) & NA & NA & NA & NA & NA & NA \\
\hline Design (ED) & 1,564 & 11,925 & 7.62 & 28 & 1,376 & 49.14 \\
\hline 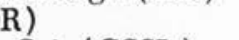 & 272 & 2,706 & 9.95 & 14 & 188 & 13.43 \\
\hline Sci. (GSSL) & 1,468 & 9,607 & 6.54 & 32 & 360 & 11.25 \\
\hline l(LSL) & 465 & 1,857 & 3.99 & 22 & 374 & 23.38 \\
\hline & 1,258 & 11,922 & 9.48 & 14 & 171 & 12.21 \\
\hline T) & 195 & 1,716 & 8.80 & 2 & 12 & 6.00 \\
\hline & 313 & 3,284 & 10.49 & $1 \overline{3}$ & $25 \overline{9}$ & 19.92 \\
\hline & 976 & 7,522 & 7.71 & 26 & 441 & 16.96 \\
\hline Crim (SW) & 425 & 2,347 & 5.52 & 10 & 71 & 7.10 \\
\hline Total & 47 & 121,426 & 6.95 & 476 & 12,962 & 27.23 \\
\hline tal & 63,803 & 484,162 & 7.59 & 499 & 6,550 & 13.1 \\
\hline & 81350 & 605,588 & 7.44 & 975 & 19,512 & 20. \\
\hline
\end{tabular}

Agriculture (AG)

Art/Anthropology (A/A)

Astronomy/Math/Stat (AMS)

Biochemistry (BIOCHEM)

Biology (BIOL)

Chemistry (CHEM)

Earth Sciences (ES)

East Asiatic (EAL)

Education/Psychology (E/P)

Engineering (ENG)

Entomology (ENT)

Environmental Design (ED)

Forestry (FOR)

Graduate Soc. Sci. (GSSL)

Library School (LSL)

Music (MUS)

Optometry (OPT)

Physics (PHY)

Public Health

Social Welfare/Crim (SW)

Branch Libraries Total

Main Library Total

TOTAL

1 Includes one $\$ 2,000$ item.

2 Includes one $\$ 1,250$ item.

schedules, were used to calculate the direct labor cost per branch and main library unit (see Tables 4 and 5). To the extent that the organization charts do not reflect the true staffing situation, and to the extent that the mean salary figures do not represent the true salaries, the data in Tables 4 and 5 are biased.

Total direct labor expenditure amounts to $\$ 3.6$ million, and of this, 22 percent is branch labor. Of the 120 Full Time Equivalent (FTE) employees in the branches, 31 percent are professional, 39 percent are nonprofessional, and 30 percent are general assistance. The 443 FTE for the Main Library is made up of 22 percent professionals, 49 percent nonprofessionals, and 29 percent general assistance.

\section{Indirect Costs: Overhead and Space}

The cost of library building space is estimated to be about $\$ 5.00$ per square foot per year. This figure is intended to represent current replacement value of the building space including equipment and fixtures and the cost of utilities and maintenance. The simplified method used to make this estimate is shown below. The numbers used were obtained from the studies by Raffel and Shishko ${ }^{3}$ and Williams, ${ }^{4}$ and from consultation with the Berkeley and University Architects Offices, the Berkeley Grounds and Building Office, and the University Real Estate Office. These numbers, however, 
TABLE 2

Size of the General Library

JuNE 30, 1968

\begin{tabular}{lrrrr}
\hline \hline \multicolumn{1}{c}{ Branch Library } & Volumes & Current Serials & Total Items ${ }^{2}$ & $\begin{array}{c}\text { Ratio of Volumes } \\
\text { to Serials }\end{array}$ \\
\hline Agriculture & 63,799 & 2,437 & 66,236 & 26.18 \\
Art/Anthropology & 27,024 & 1,158 & 28,182 & 23.34 \\
Astronomy/Math/Stat & 24,574 & 827 & 25,401 & 29.71 \\
Biochemistry & 5,427 & 140 & 5,567 & 38.76 \\
Biology & 144,090 & 3,221 & 147,311 & 44.73 \\
Chemistry & 18,342 & 335 & 18,677 & 54.75 \\
Earth Sciences & 42,199 & 977 & 43,176 & 43.19 \\
East Asiatic & 241,811 & 1,237 & 243,048 & 19.55 \\
Education/Psychology & 65,455 & 1,385 & 66,840 & 47.26 \\
Engineering & 63,162 & 1,638 & 64,800 & 38.56 \\
Entomology & 8,579 & 246 & 8,825 & 34.87 \\
Environmental Design & 50,728 & 1,293 & 52,021 & 39.23 \\
Forestry & 20,281 & 1,334 & 21,615 & 15.20 \\
Graduate Social Sciences & 39,014 & 2,616 & 41,630 & 14.91 \\
Library School & 25,520 & 2,014 & 27,534 & 12.67 \\
Music & 70,360 & 197 & 70,557 & 357.16 \\
Optometry & 2,872 & 82 & 2,954 & 35.02 \\
Physics & 15,276 & 190 & 15,466 & 80.40 \\
Public Health & 41,111 & 906 & 42,017 & 45.38 \\
Social Welfare/Crim & 12,857 & 275 & 13,132 & 46.75 \\
Branch Total & 982,481 & 22,508 & $1,004,989$ & 43.65 \\
Main Building & $2,200,562$ & 44,075 & $2,244,637$ & 49.93 \\
Total General Library & $3,183,043$ & 66,583 & $3,249,626$ & 47.81 \\
\hline
\end{tabular}

${ }^{1}$ Includes 22,692 documents.

2 A serial title is considered as an item.

TABLE 3

Salary Schedule

\begin{tabular}{cr}
\hline \hline \multicolumn{1}{c}{ Title } & $\begin{array}{c}1967 / 1968 \\
\text { Mean Salary (\$) } \\
\text { Per Year }\end{array}$ \\
\hline Professional & \\
Librarian I & $\$ 7,075$ \\
Librarian II & 8,450 \\
Librarian III & 9,975 \\
Librarian IV & 11,575 \\
Librarian V & 13,725 \\
Nonprofessional & \\
Library Assistant I & 5,250 \\
Library Assistant II & 6,078 \\
Library Assistant III & 7,044 \\
General Assistance & \\
Clerk & 4,650 \\
\hline
\end{tabular}

are not to be considered as official or certified figures in any sense, but only as representative cost figures for the purpose of analysis.

The annual cost for the Richmond Inter-Campus Library Facility $\operatorname{ICLF}(\mathrm{N})$ is estimated to be about $\$ 2.50$ per square foot per year to cover the cost of pur- chase, remodeling, equipment, utilities, and maintenance. Tables 4 and 5 summarize the space costs for the General Library.

In addition to direct labor costs, the library incurs expenses for fringe benefits and salary administrative overhead for its employees. Discussions with the University Office of the Vice President for Planning and Analysis indicated that administrative overhead is approximately 10 percent of direct labor cost. Salary administrative overhead ranges between 9 and 13 percent of direct labor, depending on job title. This study assumed that administrative overhead was 10 percent. Thus, fringe benefits plus administration total 20 percent.

Within the library itself, the costs of the librarian's office, the business office, the personnel office, and the space used by these departments were considered as part of the library overhead charge. In addition, supplies and general ex- 
TABLE 4

Labor and Space Costs-Main Library 1967/1968

\begin{tabular}{|c|c|c|c|c|}
\hline Main Library Unit & Total FTE & $\begin{array}{c}\text { Total Direct } \\
\text { Salary } \\
\text { Expenditures } \\
(\$)\end{array}$ & $\begin{array}{c}\text { Total } \\
\text { Assignable } \\
\text { Square Feet } \\
\text { (ASF) }\end{array}$ & $\begin{array}{l}\text { Total Annual } \\
\text { Space Cost } \\
\text { at } \$ 5.00 / \\
\text { Square Foot }\end{array}$ \\
\hline Acquisitions Department & 66.75 & 481,763 & 13,793 & 68,965 \\
\hline Bancroft Library & 35.075 & 249,355 & 31,599 & 157,995 \\
\hline Business Office & 17.375 & 105,742 & 4,358 & 21,790 \\
\hline Catalog Department & 76.75 & 500,420 & 6,375 & 31,875 \\
\hline Catalogs (Public) & & & 9,899 & 49,495 \\
\hline Documents Department & 26.045 & 162,584 & 31,064 & 155,320 \\
\hline General Reference Service & 17.25 & 128,369 & 3,066 & 15,330 \\
\hline $\begin{array}{l}\text { Inter-Campus Library } \\
\text { Facility North } \\
\text { (ICLF) Depository }\end{array}$ & 3.50 & 16,875 & 55,840 & $139,600^{2}$ \\
\hline Librarians Office & 6.75 & $83,891^{1}$ & 1,566 & 7,830 \\
\hline Library Pers. Office & 3.375 & 23,470 & 447 & 2,235 \\
\hline Library Photo. Service & 23.50 & 141,285 & 4,665 & 23,325 \\
\hline Loan Department & 88.125 & 464,667 & 100,901 & 504,505 \\
\hline Morrison Library & 3.745 & 20,708 & 5,487 & 27,435 \\
\hline Reading Rooms & & & 16,748 & 83,740 \\
\hline Serials Department & 69.125 & 381,007 & 31,440 & 157,200 \\
\hline Storage Selection & 1.25 & 5,813 & & \\
\hline $\begin{array}{l}\text { Undergrad. Library } \\
\text { Selection Project }\end{array}$ & 4.50 & 32,906 & 4,791 & 23,955 \\
\hline Total Main Library & 443.115 & $2,798,855$ & 322,039 & $1,470,595$ \\
\hline
\end{tabular}

1 Estimated.

2 Total annual cost of $\$ 2.50$ per square foot.

TABLE 5

Labor and Space Costs-Branch Libraries 1967/1968

\begin{tabular}{|c|c|c|c|c|}
\hline Branch Library & Total FTE & $\begin{array}{c}\text { Total Direct } \\
\text { Salary } \\
\text { Expenditure } \\
\text { (\$) }\end{array}$ & $\begin{array}{l}\text { Total } \\
\text { ASF }\end{array}$ & $\begin{array}{l}\text { Total Annual } \\
\text { Space Cost } \\
\text { at } \$ 5.00 / \\
\text { Square Foot } \\
\end{array}$ \\
\hline Agriculture & 4.805 & 33,009 & 7,746 & 38,730 \\
\hline Art/Anthropology & 4.045 & 24,387 & 5,307 & 26,535 \\
\hline Astronomy/Math/Stat & 3.94 & 23,783 & 4,009 & 20,045 \\
\hline Biochemistry & .512 & 4,014 & 1,503 & 7,515 \\
\hline Biology & 14.225 & 81,617 & 21,480 & 107,400 \\
\hline Chemistry & 3.08 & 19,276 & 11,025 & 55,125 \\
\hline Earth Sciences & 3.08 & 20,104 & 5,782 & 28,910 \\
\hline East Asiatic & 18.875 & 153,834 & 13,698 & 68,490 \\
\hline Education/Psyc. & 13.50 & 84,532 & 13,308 & 66,540 \\
\hline Engineering & 5.875 & 35,498 & 6,125 & 30,625 \\
\hline Entomology & 1.52 & 9,947 & 1,796 & 8,980 \\
\hline Environmental Des. & 8.08 & 54,376 & 14,522 & 72,610 \\
\hline Forestry & 4.97 & 37,436 & 5,319 & 26,595 \\
\hline Grad. Soc. Sci. & 11.69 & 77,415 & 23,713 & 118,565 \\
\hline Library School & 2.75 & 17,679 & 3,321 & 16,605 \\
\hline Music & 6.375 & 44,096 & 8,858 & 44,290 \\
\hline Optometry & 1.03 & 6,897 & 1,014 & 5,070 \\
\hline Physics & 3.58 & 23,958 & 4,833 & 24,165 \\
\hline Public Health & 5.64 & 36,149 & 7,873 & 39,365 \\
\hline Social Welfare & 3.20 & 17,439 & 4,205 & 21,025 \\
\hline Total Branch Library & 120.772 & 805,446 & 165,437 & 827,185 \\
\hline Total Main Library & 443.115 & $2,798,855$ & 322,039 & $1,470,595$ \\
\hline TOTAL & 563.887 & $3,604,301$ & 487,476 & $2,297,780$ \\
\hline
\end{tabular}


Cost of on-campus or nearby real estate Total building construction project cost

Total building and site cost

Assignable space factor with 80 percent utilization

Effective cost of assignable space

Cost of fixtures, furniture, shelving, etc.

Total initial cost of space and furnishings

Capital recovery factor

Equivalent annual cost of space and furnishings

Annual cost of utilities and maintenance

Total annual cost for library building space
$\$ 12.00$ per gross sq. $\mathrm{ft}$. 38.00 per gross sq. $\mathrm{ft}$.

$\$ 50.00$ per gross sq. $\mathrm{ft}$.

1.25

$\$ 62.50$ per sq. ft. 4.00 per sq. $\mathrm{ft}$.

$\$ 66.50$ per sq. ft. 0.06

$\$ 3.99$ per sq. ft. per yr. 1.00 per sq. ft. per yr.

$\$ 4.99$ per sq. ft. per yr. penses as well as equipment and fixtures were included in the overhead charge and allocated to library units on a salary basis. The overhead charges for these departments and items amounted to 21 percent. The total overhead charge for library units was 41 percent ( 20 percent +21 percent).

\section{Processing Cost Centers:}

Acquisition and Cataloging Costs

As materials are introduced into the processing centers of the library, they undergo transformations which ultimately result in items ready for circulation. Figure 2 shows the flow of items through the processing centers, and Table 6 indicates unit costs. The monographs and/or serials enter at each processing center. To these "raw materials" is added a labor, space, and overhead charge. Thus, as a unit passes out of the processing center, a value is added corresponding to the cost of processing the item.

For purposes of the model, monographs are considered to be acquired from two sources-purchases and gifts. Purchased monographs enter the system at a cost of $\$ 7.44$ per item. Gift monographs enter at zero cost per item. To the direct material cost for purchased monographs is added a labor and space charge of $\$ 3.04$ per item. The $\$ 3.04$ is the cost for the Administrative and Processing Divisions of the Acquisitions
Department, plus overhead.

New monographs enter the cataloging department from the Gifts Division and the normal acquisition ordering procedure. Once in the cataloging department, a labor, space, and overhead charge of $\$ 5.40$ per monograph is added. Binding, selection, and other miscellaneous charges are also added.

A monograph acquired by a branch has a final cost of $\$ 25.00$, while a monograph acquired by the main library costs $\$ 19.85$.

Similar flows can be observed for serials and documents. A paid serial has an

\begin{tabular}{lrr}
\multicolumn{3}{c}{ TABLE 6} \\
UNIT Costs \\
\hline \hline \multicolumn{3}{c}{ Monographs }
\end{tabular}

- Columns do not add to total since not all units are processed by all departments.

initial subscription cost of $\$ 20.00$. After cataloging for a new serial and proc- 
essing (check in/entering) for all serials, the branch cost is raised to $\$ 39.03$ and the main library cost becomes \$33.87.

Miscellaneous charges include binding expenditures as well as postage, insurance, and taxes on acquisitions. Binding charges are made up of the cost to operate the bindery, the Bindery Preparation Division, and the Binding Pickup Department. Including space and overhead charges, this amounts to $\$ 337,197$ for 55,880 items bound (excluding mending). When the total expenditure is divided between monographs and serials in the ratio 20,899 to 34,981 ( 1 to 1.67 ) and the resulting cost divided by the total monograph and serial items processed, a cost of $\$ 1.54$ per monograph and $\$ 5.03$ per serial results. These amounts represent proportional charges for future binding that a processed item incurs.

In addition to binding and postage charges, a received serial has added to it a charge reflecting its check-in cost. This amounts to $\$ 3.24$ per serial title per year.

\section{Service Cost Centers: \\ Main Library and Branch Libraries Costs}

Once the labor and space costs have been established for the processing functions, it is then possible to determine the service costs and the total library costs. Tables 7 and 8 summarize the total library cost for the system. Out of a total of $\$ 8.3$ million, $\$ 3.7$ million (46 percent) is spent in the process of acquisition of materials. Of this, only $\$ 1.2$ million (14 percent) is for the purchase of raw materials, i.e., monographs and serials.

Total acquisition cost of $\$ 3.7$ million has three components: materials cost, labor cost, and space cost. Materials are either monographs or serials, and enter the system at a unit price of $\$ 7.44$ and
$\$ 20.00$, respectively. Gift items enter at zero cost. Acquisition labor cost includes the cost of all units involved in processing the items; i.e., acquisitions processing, cataloging, serials processing, documents processing, and branch processing. The space cost is that associated with each of the processing units.

Branch labor acquisition cost was determined by means of interviews with each branch librarian. The librarian was asked to indicate what percentage of time each employee spent in the acquisitions process. This time was intended to reflect the cost of selection of materials, typing of orders, and other associated tasks. The cost of branch processing of items (cataloging, filing, etc.) was estimated from a survey of three branch libraries.

Service labor and service space costs reflect the cost of providing service to the patron. This is in distinction to the total processing cost which reflects the cost of obtaining and processing raw materials.

\section{Comparison of the Costs of Circulation, Holding, AND ACQuisition}

Several measures have been selected for use in evaluating the performance of the library and aiding in planning and analysis. If the total cost for the branch service operations is divided by the total number of items held, a measure of the holding and acquisition cost per item is obtained. Figure 3 plots this relationship for the branch libraries. The plot exhibits a declining cost per item held as the number of items held by the library increases. Evidently some economies of scale are present. The smallest branch library, Optometry, has the second highest cost among all branches (\$7.05). (Libraries cited are circled in subsequent figures to aid the reader in interpreting the data.) The Graduate Social Science Library has the 
TABLE 7

Total Library Cost-Branch Libraries $1967 / 1968$

\begin{tabular}{lrrrr}
\hline \hline \multicolumn{1}{c}{ Branch } & $\begin{array}{c}\text { Service } \\
\text { Labor } \\
\text { Cost }\end{array}$ & $\begin{array}{c}\text { Service } \\
\text { Space } \\
\text { Cost }\end{array}$ & $\begin{array}{r}\text { Total } \\
\text { Processing } \\
\text { Cost }\end{array}$ & $\begin{array}{r}\text { Total } \\
\text { Library } \\
\text { Cost }\end{array}$ \\
\hline Agriculture & 21,372 & 37,749 & 115,916 & 175,037 \\
Art/Anthropology & 18,886 & 25,931 & 66,572 & 111,389 \\
Astronomy/Math/Stat & 23,938 & 19,674 & 42,553 & 86,165 \\
Biochemistry & 3,997 & 7,450 & 7,364 & 18,811 \\
Biology & 84,942 & 106,226 & 143,041 & 334,209 \\
Chemistry & 23,129 & 54,967 & 17,850 & 95,946 \\
Earth Sciences & 16,859 & 28,462 & 51,007 & 96,328 \\
East Asiatic & 171,330 & 66,714 & 165,330 & 403,374 \\
Education/Psychology & 93,595 & 65,543 & 102,532 & 261,670 \\
Engineering & 31,657 & 29,908 & 82,706 & 144,271 \\
Entomology & 12,131 & 8,906 & 9,601 & 30,638 \\
Environmental Design & 53,969 & 71,728 & 91,641 & 217,338 \\
Forestry & 40,311 & 26,109 & 59,216 & 125,636 \\
Graduate Social Sciences & 77,108 & 117,313 & 140,752 & 335,173 \\
Library School & 5,646 & 15,854 & 90,856 & 112,356 \\
Music & 50,456 & 43,833 & 70,476 & 164,765 \\
Optometry & 7,515 & 4,984 & 8,325 & 20,824 \\
Physics & 29,777 & 24,009 & 15,666 & 69,452 \\
Public Health & 36,078 & 38,785 & 61,061 & 135,924 \\
Social Welfare & 19,022 & 20,808 & 21,934 & 61,764 \\
Branch Total & 821,718 & 814,953 & $1,364,399$ & $3,001,070$ \\
Main Total & $1,618,531$ & $1,282,612$ & $2,425,481$ & $5,328,624$ \\
TOTAL & $2,440,249$ & $2,097,565$ & $3,789,880$ & $8,327,694$ \\
\hline
\end{tabular}

- Includes materials, labor, space, and overhead costs connected with nonservice activities.

TABLE 8

Total Library Cost-Main Library $1967 / 1968$

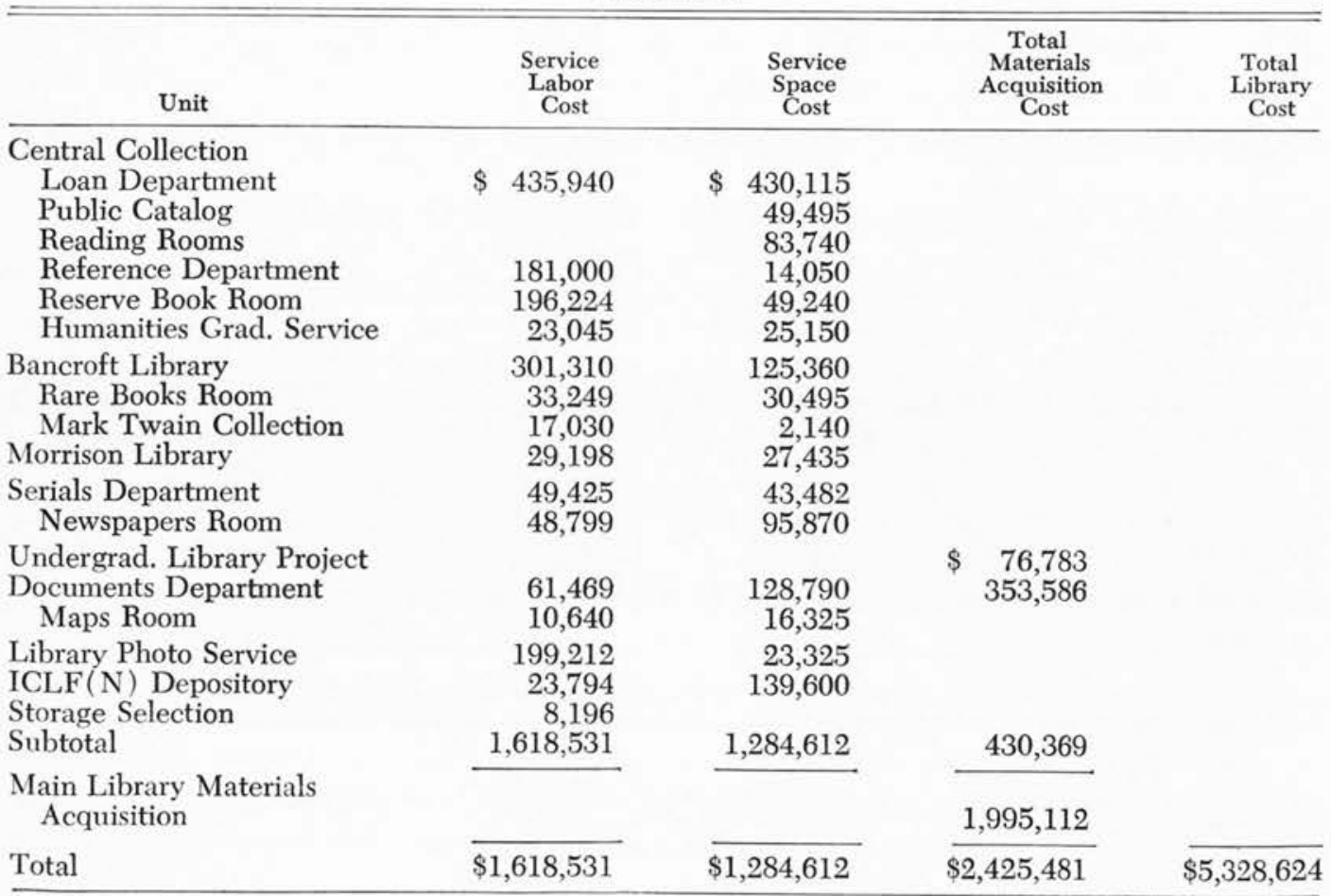




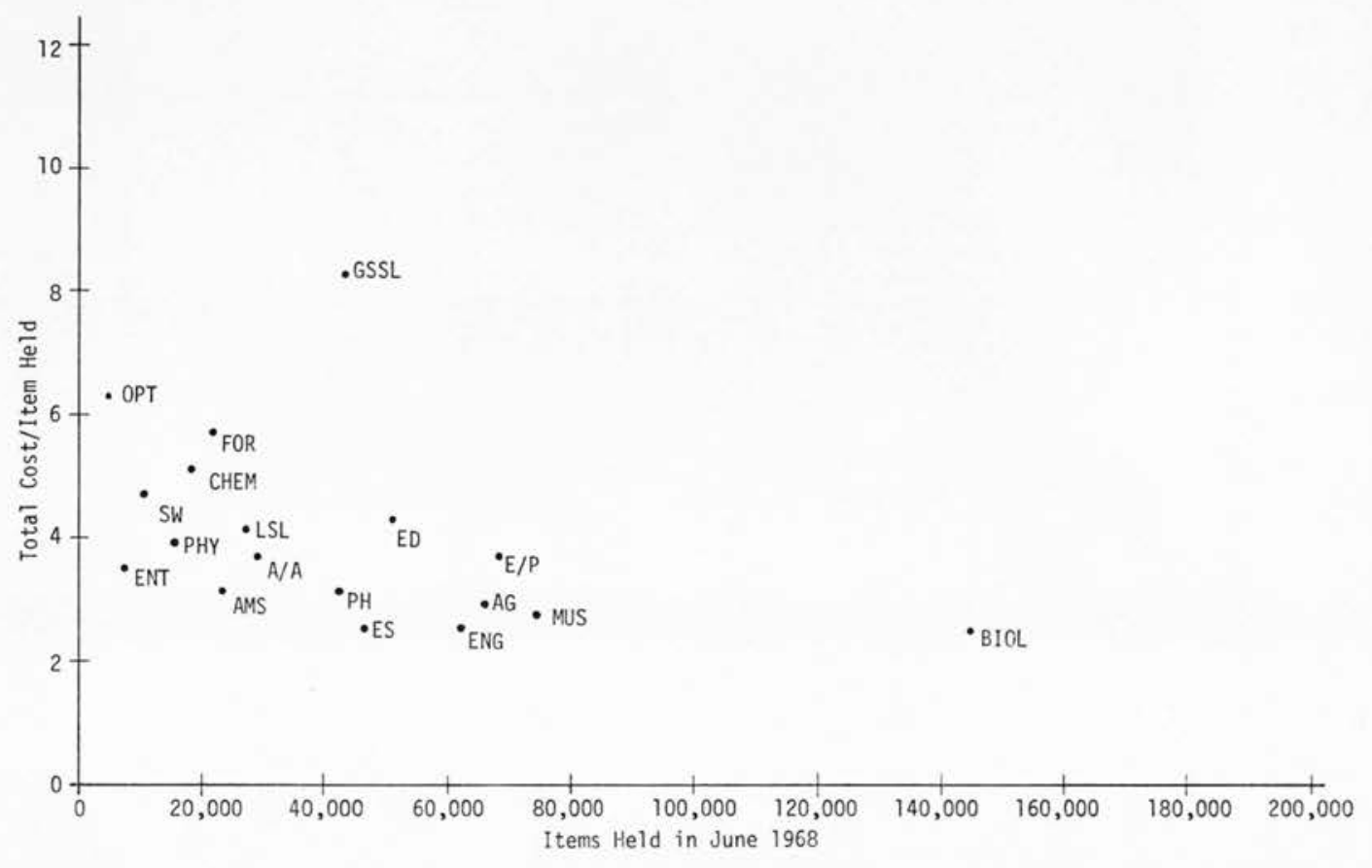

Figure 3

Total Cost PER Item Held

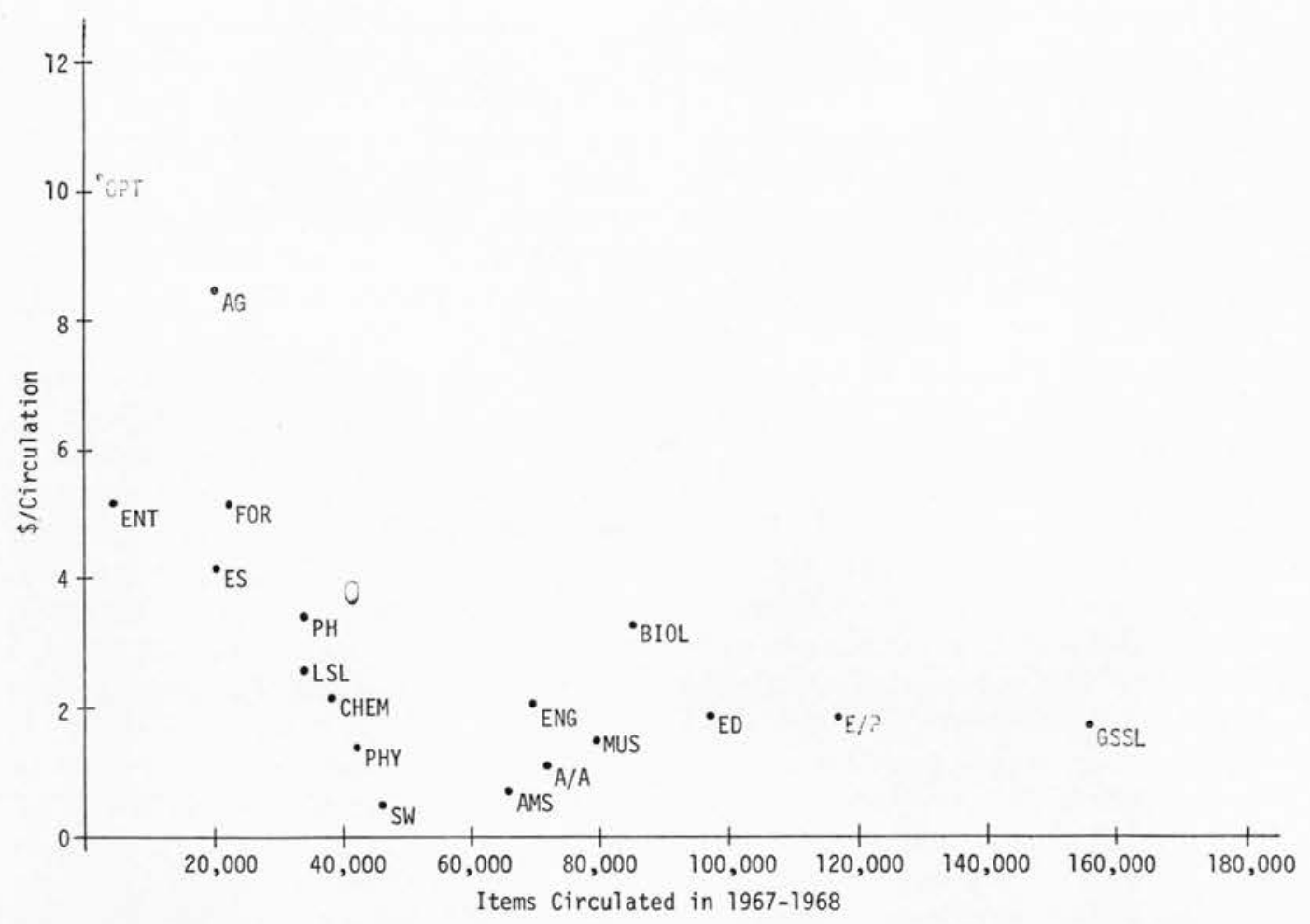

Figure 4

Total Cost per Unit of Circulation 


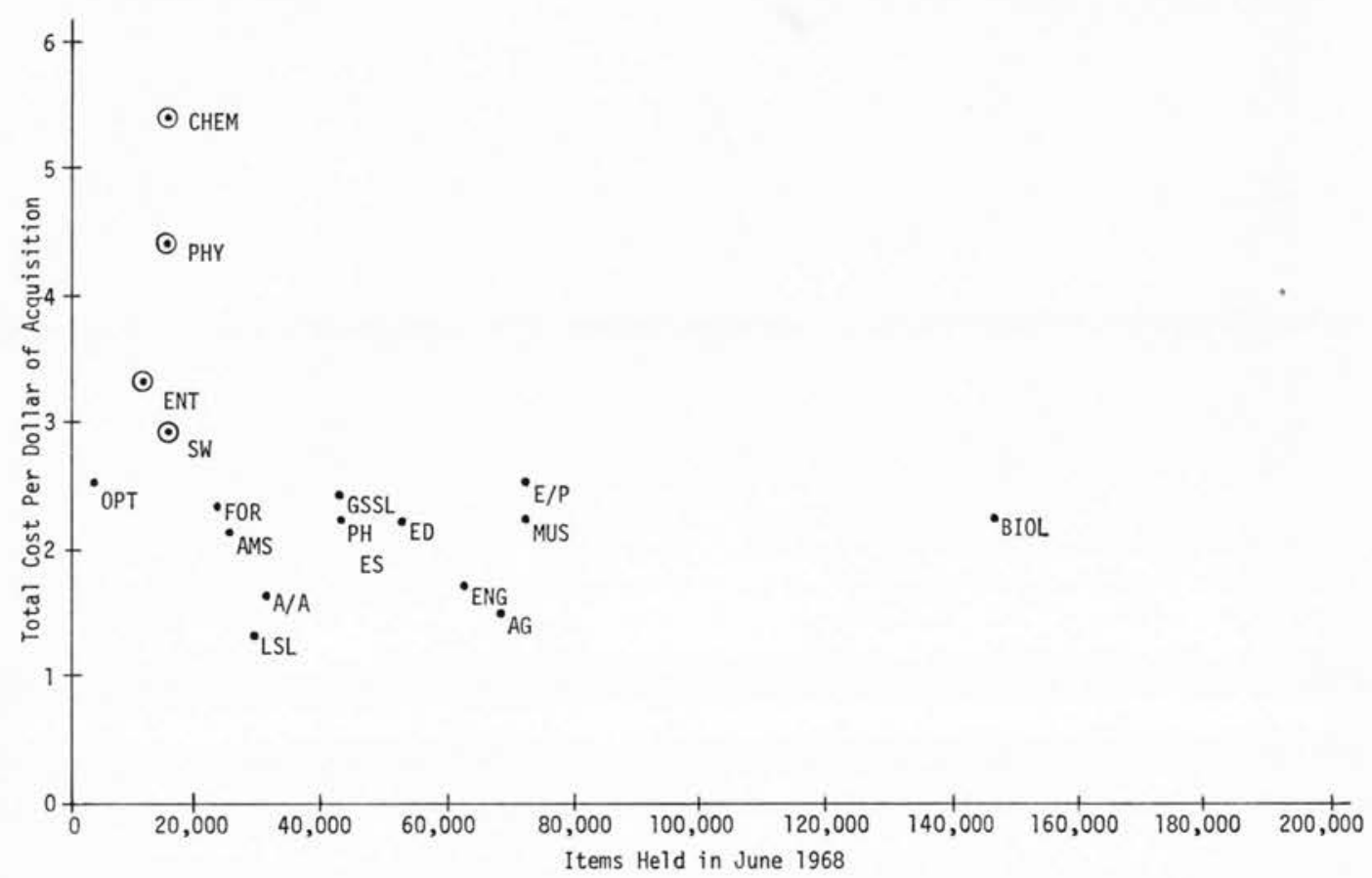

Figure 5

Total Cost per Dollar of Acquisition

highest cost per item held, but this can be accounted for by the large amount of unused stack capacity of the library. The largest branch library (not shown on graph), East Asiatic, has the lowest cost per item held (\$1.66).

Branch libraries average $\$ 2.99$ while the main library averages $\$ 2.37$ per item held. The overall average holding cost per item is $\$ 2.56$.

The total cost per unit of circulation is plotted for branch libraries in Figure 4. Each data point represents the total cost of the branch service center divided by the total circulation for that branch. The average cost per unit of circulation is $\$ 3.53$ for the General Library. Main library cost is $\$ 4.16$ per item, while branch cost is $\$ 2.77$.

The minimum cost per unit of circulation is reached for branches having 50,000 to 70,000 circulations per year. The highest cost per unit of circulation is recorded for the branch library having the smallest circulation. The branch library with the highest circulation, the Graduate Social Sciences Library, has a cost of $\$ 2.07$ per unit of circulation as compared with the $\$ 2.77$ average branch cost.

Total cost per dollar of acquisition is calculated as the total library cost by branch divided by the total acquisition cost for that branch. A lower cost per dollar of acquisition reflects the fact that more money is being put into materials than labor or space. Figure 5 shows that the Library School Library devotes a major share of its resources to acquisition. The Chemistry library, on the other hand, spends a small amount of money on acquisitions relative to labor and space. In general, small branches (Social Welfare, Entomology, Physics, and Chemistry) exhibit a much higher than average cost per dollar of 


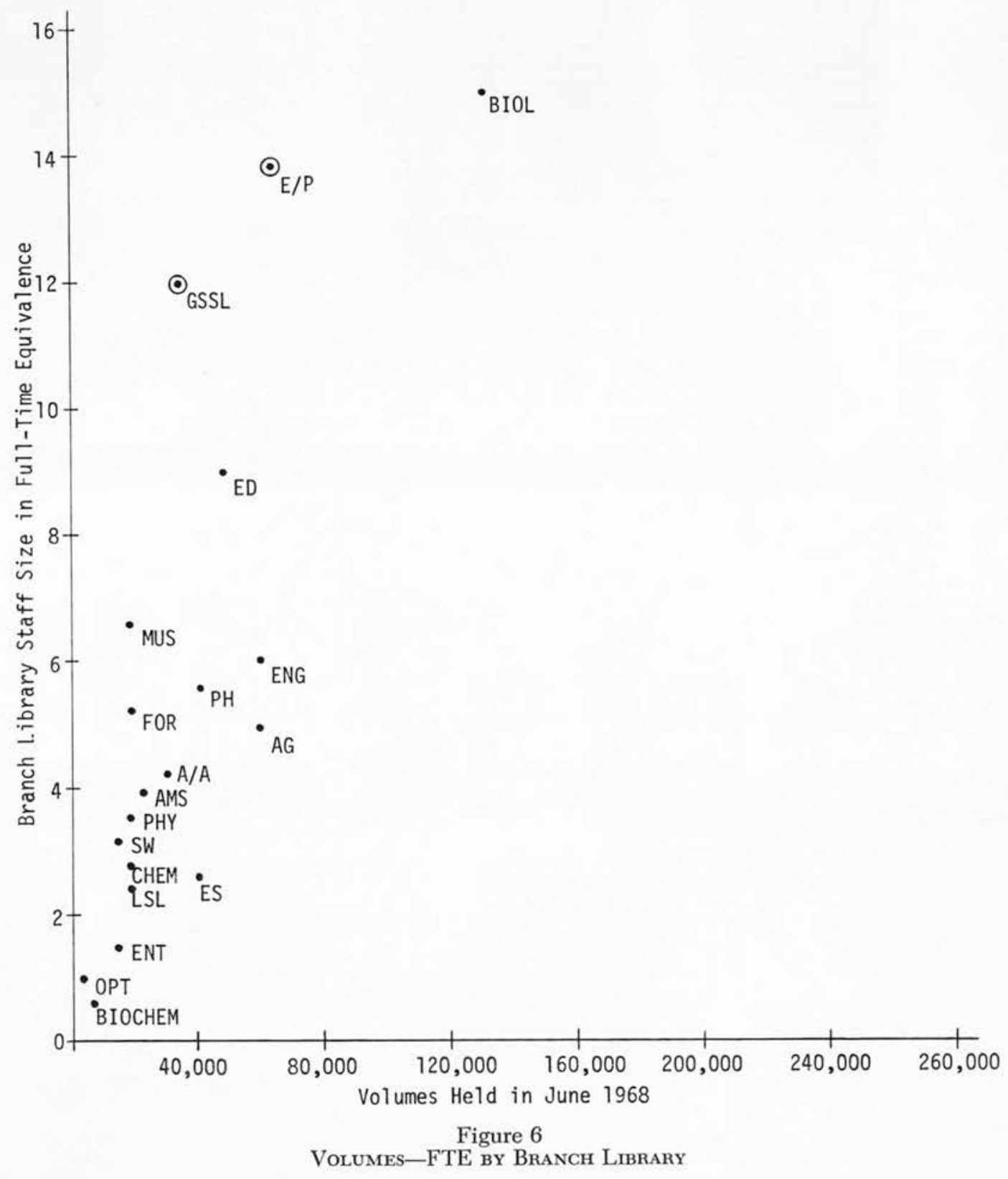

acquisition. The cost for the remaining branch libraries seems to stabilize in the $\$ 1.20$ to $\$ 2.70$ range.

Comparisons of Labor and Space Costs

Nearly $\$ 3.6$ million out of $\$ 8.3$ million was spent for direct labor in the
General Library in 1967/1968. Since this constitutes a relatively large expenditure, it is important to try to develop tools for detecting significant changes in staffing needs.

The relation between FTE and the number of volumes held is presented in Figure 6. As the number of volumes 


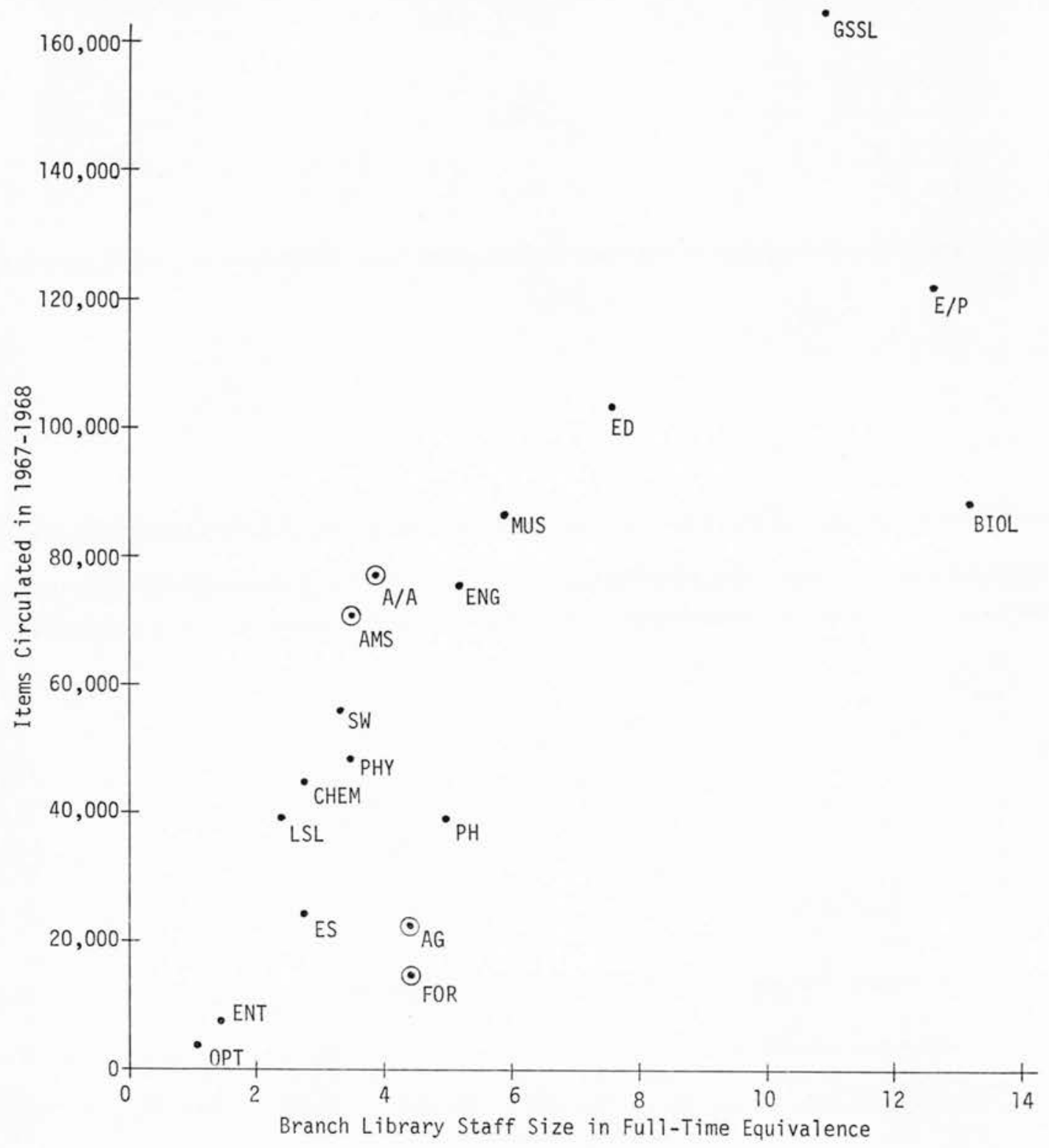

Figure 7

FTE-Circulation

held increases, FTE staff increases. This relationship may be due to the manner in which staff is allocated to the branches.

When FTE and circulation by branch are compared (Figure 7), the same increasing pattern emerges. If a curve were fitted to the data of Figure 6 , it would seem that the Graduate Social Sciences library and the Education/
Psychology library fall in line with the staffing-circulation relationships of the other branches.

Interviews with the Art/Anthropology and Astronomy/Mathematics/Statistics librarians have indicated a shortage in FTE for the amount of circulation of their respective branches. This seems to be confirmed by Figure 7. In addition, the graph indicates that Agricul- 


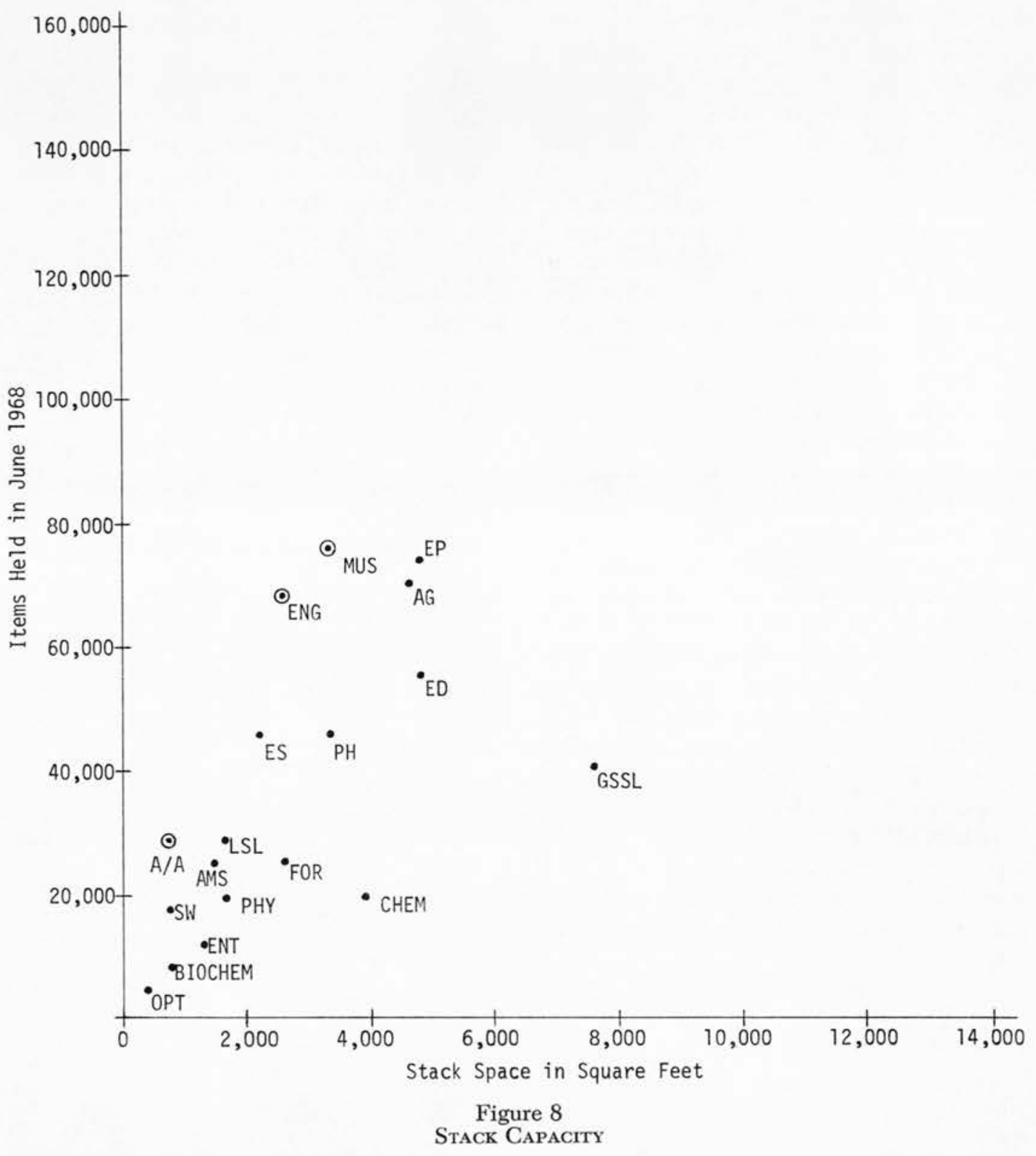

ture, Biology, and Forestry are overstaffed for the amount of circulation.

The storage of materials constitutes a second area in which planning and control must be exercised. Since facilities cannot be constructed in short periods of time, management must be in a position to predict when a branch will no longer be able to store all the items it would like.

The stack capacity (in square feet) for each of the branches is plotted against the total items held by that branch in Figure 8. From the graph it is apparent that the Chemistry and Graduate Social Sciences library have room for expansion while Art/Anthropology, Engineering, and Music seem to be relatively crowded.

\section{SUMMARY}

A cost-flow accounting model has been presented and data from the University of California Berkeley General Library 
has been used to illustrate the model's applicability. Unit and total cost comparisons have been made and evaluative tools have been proposed for use in library management. From the analysis, a number of conclusions can be drawn.

With respect to circulation, holding, and acquisition costs, it appears that a lower cost per item held is found in branch libraries having a large number of items. In addition, branch libraries with a circulation in the range of 50,000 to 70,000 are found to have the minimum cost per unit of circulation. The analysis also indicates that small branch libraries spend more of their resources on acquisition of material than they devote to labor.

Analyses of labor and space costs also yield useful planning information. From these costs it is possible to detect staffing needs and staffing patterns. This is done by determining the relationship between FTE and circulation and FTE and items held for the branch libraries. In addition, by determining the relation between volumes held and stock capacity across all branches, the librarian is in a position to see where construction resources can be used most effectively, or where collection weeding might take place,

\section{ACKNOWLEDGMENTS}

The authors acknowledge the generous assistance of Dr. James E. Skipper, university librarian, for making available all necessary data for the cost analysis. Mrs. Helen M. Worden, associate university librarian, was especially helpful in clarifying many of the problems incurred in the analysis of the Berkeley library. Miss Coralia Serafim conducted the survey of branch librarians. Dr. Robert M. Hayes and Dr. Patrick Wilson made valuable suggestions to preliminary drafts of this document.

\section{Bibliography and References}

1. Landau, Herbert B. "The Cost Analysis of Document Surrogation: A Literature Review," American Documentation 20:302-10 (Oct. 1969).

2. Penner, Rudolph J. "The Practice of Charging Users for Information Services: A State of the Art Report," Journal of the American Society for Information Science 21:67-74 (Jan.-Feb. 1970).

3. Raffel, Jeffrey, and Shisko, Robert. Systematic Analysis of University Libraries. M.I.T. Press, 1969.

4. Williams, Gordon. Library Cost Models: Owning Versus Borrowing Serial Publications. Center for Research Libraries: Chicago, 1968. PB 182304. 